\title{
Factors affecting the severity of motor vehicle traffic crashes involving young drivers in Ontario
}

\author{
Yang Mao, Jun Zhang, Glenn Robbins, Kathy Clarke, Miu Lam, William Pickett
}

\begin{abstract}
Objectives-To assess the factors affecting the severity of motor vehicle traffic crashes involving young drivers in Ontario.

Population-Ontario young drivers, aged 16 to 20 , involved in traffic crashes resulting in injury, between 1 January 1988 and 31 December 1993, on public roads in Ontario.
\end{abstract}

Methods-Population based case-control study. Cases were fatal injury, major injury, and minor injury crashes involving young drivers. Controls were minimal injury crashes involving young drivers. Cases and controls were obtained retrospectively from the Canadian Traffic Accident Information Databank. Unconditional logistic regression was used for data analysis.

Results-Factors significantly increasing the risk of fatal injury crashes include: drinking and driving (odds ratio (OR) 2.3), impairment by alcohol (OR 4.8), exceeding speed limits (OR 2.8), not using seat belts (OR 4.7), full ejection from vehicle (OR 21.3), intersection without traffic control (OR 2.2), bridge or tunnel (OR 4.1), road with speed limit $70-90 \mathrm{~km} /$ hour (OR 5.6) or $100 \mathrm{~km} / \mathrm{hour}$ (OR 5.4), bad weather (OR 1.6), head-on collision (OR 80.0), and overtaking (OR 1.9). Results of the same model applied to major and minor injury crashes demonstrated consistent but weaker associations with decreasing levels of crash severity.

Cancer Bureau, Laboratory Centre Health Canada, Tunney's Pasture, Ottawa, Ontario, Canada KIA OL2 Y Mao

J Zhang

K Clarke

Road Safety and Motor Vehicle Regulations, Transport Canada G Robbins

Queen's University, Kingston, Ontario, Canada: Department of Community Health and Epidemiology M Lam

Departments of Community Health and Epidemiology and Emergency Medicine

W Pickett

Correspondence to Dr Mao.

Keywords: motor vehicle traffic crashes; young driver; risk factor; case-control study.

Fourteen per cent of driver fatalities associated with motor vehicle traffic crashes in the province of Ontario involve drivers between the age of 16 and 20 even though only $7 \%$ of motor vehicle drivers are in this age group. ${ }^{1}$

Risk factors for motor vehicle traffic crashes have been documented in previous studies, ${ }^{2-8}$ including driver characteristics and behaviors, environmental factors, crash characteristics, focused on young male drivers, ${ }^{9}$ drinking and driving, ${ }^{1011}$ speeding, ${ }^{1213}$ not using seat belts, ${ }^{14} 15$ and driving on weekends and at night, ${ }^{16} 17$ all of which are positively associated with increased risk of fatal injury. The role of crash type, ${ }^{18}$ vehicle type, ${ }^{19}$ and manoeuvre, however, has not been studied extensively. The effect of posted road speed limits ${ }^{2021}$ and weather conditions ${ }^{22} 23$ on the probability of injury or mortality is controversial.

Unlike previous reports, this epidemiologic study quantifies the strength of association between potential risk factors and crash severity - fatal, major, or minor-compared with minimal crash severity (for definitions, see table 1). It also examines how these risk factors are inter-related.

\section{Materials and methods}

DATABASE

The Canadian Traffic Accident Information Databank (TRAID, version 3), operated and managed by Transport Canada, compiles surveillance data from police reports of traffic crashes. It includes crash, vehicle, and personal data for individuals involved in collisions that occur on Canadian public roads and result in injury. ${ }^{24}$

Crash data include time (month, day, hour), conditions (road, weather, light), and crash configuration (for example head-on). Vehicle data describe the type of vehicle and manoeuvres involved. Personal data include road user (for example driver, passenger), age, sex, use of seat belts, alcohol involvement (drinking and driving, that is blood alcohol concentration (BAC) $<0.08 \%$, or impaired, that is BAC $\geqslant 0.08 \%$ ), speeding, and severity of injuries (fatal, major, minor, and minimal) for individuals involved in the crash. (BAC is determined by various means including blood test, breath test, urine test, or police observation alone.)

Injury severity data are provided through police observations at the scene and follow up through hospital records at 30 days if the injured person was admitted to hospital. Fatal injury is defined by police as death occurring and type of vehicles involved. Studies have
Table 1 Levels of crash severity

\begin{tabular}{cc}
\hline $\begin{array}{c}\text { Fatal injury } \\
\text { crash }\end{array}$ & $\begin{array}{c}\text { At least one person (driver or passenger) } \\
\text { killed (within } 30 \text { days) by injuries } \\
\text { sustained in the crash }\end{array}$ \\
$\begin{array}{c}\text { Major injury } \\
\text { crash }\end{array}$ & $\begin{array}{c}\text { At least one person injured and admitted } \\
\text { to hospital but no fatalities }\end{array}$ \\
$\begin{array}{c}\text { Minor injury } \\
\text { crash }\end{array}$ & $\begin{array}{c}\text { At least by one person requiring medical } \\
\text { care but no fatalities or injuries requir } \\
\text { ing hospitalization }\end{array}$ \\
$\begin{array}{c}\text { Minimal injury } \\
\text { crash }\end{array}$ & $\begin{array}{c}\text { At least one person injured (for example } \\
\text { minor abrasions/bruises) but no medical } \\
\text { attention required and no other more } \\
\text { severe injuries }\end{array}$ \\
\hline
\end{tabular}


within 30 days from injuries sustained in the crash. Major injury includes injury that requires medical treatment in hospital. Minor injury includes injury that requires medical attention (for example in emergency room) but not hospitalization. Minimal injury refers to injury such as abrasions and bruises that do not require medical attention.

\section{CASE-CONTROL STUDY}

A population based case-control study was conducted using all motor vehicle traffic crashes involving drivers aged 16 to 20 and associated with automobiles, vans, or light trucks in Ontario between 1988 and 1993. Crashes involving pedestrians, cyclists, large trucks, buses, motorcycles, and other types of vehicle were excluded. Crashes that involved no injury and/or property damage alone were not included because such data were not available for this study.

Case and control status was determined by crash severity, that is cases were fatal, major, or minor injury crashes and controls were minimal injury crashes (see table 1). The outcome, crash severity, reflects the most severe injury sustained by any individual involved in the crash. Environmental, crash, and vehicle risk factors are also related to the crash; personal risk factors, however, describe young driver characteristics and behaviors (for example BAC or speeding).

A primary analysis compared cases, that is fatal injury crashes involving young drivers, and controls, that is minimal injury crashes involving young drivers. Secondary analyses then compared major and minor injury crashes to minimal injury crashes. A total of 1009 fatal injury crashes and 41663 minimal injury crashes involving young drivers aged 16 to 20 were identified from TRAID during the study period. In addition, 6646 major injury crashes and 33723 minor injury crashes were used for secondary analyses.

This exploratory study included all potential risk factors available in TRAID: age, sex, drinking and driving, impaired by alcohol, speeding, use of seat belts, crash time and conditions at the crash site, crash configuration, and vehicle type and manoeuvre (see table 2).

\section{STATISTICAL ANALYSES}

In the primary analysis, the crude odds ratio (OR) with $95 \%$ confidence interval (CI) were calculated for each of these risk factors, comparing fatal injury crashes to controls. For each variable under study (for example road surface condition), the risk of fatality for each subcategory (for example wet, snow or ice, and other) was compared with the reference category for that variable (for example dry surface), denoted by $O R=1$ in table 2 . Relationships between the risk factors for the population in the primary analysis (that is fatal cases and controls) were also tabulated using contingency tables.

Although the literature shows that driver characteristics, environment, crash type, and vehicle type are all associated with fatal injuries, it is not clear which of these factors play the most important parts in predicting fatal injury crash. For this reason, we adopted an exploratory approach using a stepwise. procedure to select the significant variable from all potential risk factors available in TRAID, rather than developing a model base宩 on specific hypotheses. Unconditional multi产 variate logistic regression analysis was used $t \overline{\mathrm{D}}$ generate an exploratory model and to calculate point and $95 \%$ CI estimates of ORs. ${ }^{2526}$

The multivariate analysis was limited $t \vec{\nabla}$ crashes for which there were no missing values. Potential interaction between risk factors, fow example, between gender and drinking, gendē and speeding, and drinking and speeding wer also investigated using the log likelihood test. $\overrightarrow{ }$

In the secondary analyses, the same moded developed in the primary analysis was applie@ to compare associations for major and minor injury crashes to minimal injury crashes.

\section{Results}

With the exception of driver age and road category, all risk factors considered in thi $\$$ study were significantly associated with the risk of fatal injury crashes in the bivariate analysise After adjusting for potential risk factors in the multivariate logistic regression model, thes risk factors were still significant with the exception of the sex of young drivers. Overallo the relationships held, but less strongly, fo $\overrightarrow{\vec{B}}$ major injury crashes and minor injury crashes? Table 2 presents the ORs for risk factors fo various levels of crash severity. Selected results. of the inter-relationships between risk factors are described in the text below.

\section{DRIVER CHARACTERISTICS}

In the bivariate analysis, we observed tha crashes involving young male drivers were almost twice as likely to be fatal as those involving young female drivers. However, this association was not significant after controlling for other potential factors, suggesting thaf other factors contribute to the differences inp severity of crash betwen males and females. InE. the study population used for the primars analysis (that is fatal cases and controls), $6.3 \%$ of young male drivers were using alcohol, $4.3 \%$ were exceeding the speed limit, and $7.2 \%$ were not using seat belts, compared with $1.8 \%$ $1.6 \%$, and $4.5 \%$, respectively, of young female drivers. We found that there was no significant? effect modification between gender and alco: hol use or gender and speeding (change in log likelihood 1.5, degree of freedom $(\mathrm{df})=3, \mathrm{p}=\mathrm{D}$ 0.68 and $2.8, \mathrm{df}=1, \mathrm{p}=0.10$, respectively) $\stackrel{\mathrm{D}}{\mathrm{Q}}$ that is young females and males who were drinking or speeding had an equal risk of being involved in a fatal crash.

Alcohol consumption increased the risk of fatality in crashes by a factor of 2.3 for drinking and driving and 4.8 for impairment, and almost doubled the risk of major injury. Most alcohol related crashes occurred at night, that 
is $8 \mathrm{pm}$ to $4 \mathrm{am}(72 \%)$, or on weekends, that is Friday to Sunday $(73 \%)$. Young drivers using alcohol were seven times as likely to exceed the speed limit, and driving over the speed limit almost tripled (OR $=2.8)$ the risk of involvement in fatal injury crashes. When effect

Table 2 Factors affecting the severity of motor vehicle traffic crashes involving young drivers in Ontario, 1988-93

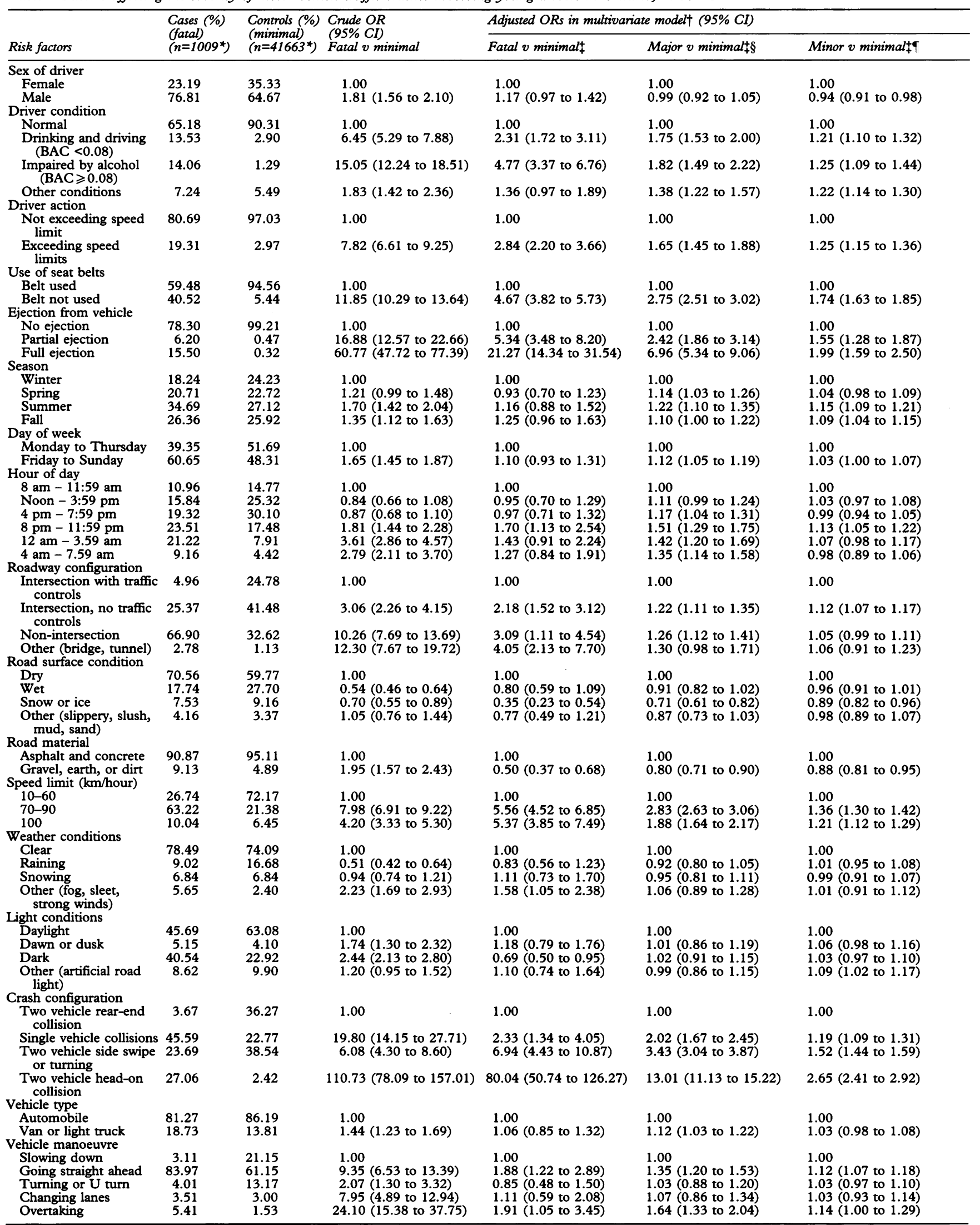

*Numbers are slightly different for each exposure due to the missing values $(<0.01 \%)$.

tThe multivariate analysis was limited to crashes for which there were no missing values.

†Each of ORs has been adjusted for all other variables in the table.

§There were 6646 major injury crashes in the study period.

ๆThere were 33723 minor injury crashes in the study period. 
modification between alcohol and speeding was examined in the multivariate model, however, it was not statistically significant (change in log likelihood 3.0, df $=3, \mathrm{p}=$ 0.39 ). Of crashes involving speeding, $63 \%$ were single vehicle collisions, compared with $22 \%$ of those not involving speeding.

Drivers who were not wearing seat belts were 4.7 times as likely to be involved in fatal crashes as those who were wearing seat belts. Seat belt use was also significantly associated with crashes of less severity. Ejection from the vehicle was a strong risk factor for fatal injury and was found to be related to not using a seat belt. The log likelihood test used in the logistic regression model indicated that ejection increased the risk of fatal injury crashes independent of seat belt use (change in log likelihood 268, df $=2, \mathrm{p}<0.0001$ ). Both risk factors were used in the final model.

\section{ENVIRONMENT}

Crashes occurring between the hours of $8 \mathrm{pm}$ and midnight were 1.7 times as likely to be fatal crashes after controlling for all potential risk factors in the logistic model. In addition, major injury crashes were more likely to occur in summer months, on weekends, or during night hours (ORs from 1.1 to $1.5, \mathrm{p}<0.05$, see table 2).

Crashes at intersections without traffic controls were twice as likely to be fatal as those at intersections with controls and crashes occurring on roads away from intersections were three times as likely to be fatal as those at intersections with controls.

Slippery, slushy, or other bad road surfaces did not increase the risk of fatal injury crashes; in fact, crashes on roads with snowy or icy surfaces were less likely to be fatal than those on dry roads. This does not necessarily mean that traffic crashes are less likely to happen on snowy or icy roads, but that collisions occurring on such roads tend to be less severe. Similarly, fatal injury crashes were less likely to occur on gravel or dirt roads. On the other hand, bad weather, such as fog, sleet, or strong winds, did increase the risk of fatal crashes slightly and significantly, even after controlling for other risk factors.

After controlling for all risk factors including speeding, crashes on roads with speed limits over $70 \mathrm{~km} /$ hour had a significantly increased risk of fatality compared with roads with limits below $70 \mathrm{~km} /$ hour. Roads with speed limits of $100 \mathrm{~km} /$ hour did not have an increased risk of fatality compared with those with speed limits between 70 and $90 \mathrm{~km} /$ hour. Moreover, analysis of the inter-relationship of risk factors indicates that crashes on roads with higher speed limits (that is $\geqslant 70 \mathrm{~km} /$ hour) were 2.4 times as likely to involve exceeding of speed limits as those on roads with lower speed limits.

\section{CRASH CHARACTERISTICS}

Head-on collisions increased the risk of fatality by a factor of 80 . Two vehicle side swipe and single vehicle collisions were also at higher risk of fatality compared with two vehicle rear-end collisions (see table 2). Further examination of the inter-relationship of crash figuration and other risk factors indicated that head-on collisions were more likely to involve alcoh consumption $(6.9 \%)$, speeding $(3.4 \%)$, dark ness $(31.7 \%)$, and bad weather conditions (that is fog, sleet and strong wind, $6.0 \%$ compared with rear-end collisions $(1.6 \%$ $1.4 \%, 14.8 \%$, and $1.7 \%$, respectively). VehE cles going straight ahead or overtaking anothe vehicle were more likely to be fatal than those where vehicles were slowing down. Making turns (right; left, $U$ ) and changing lanes were not statistically associated with increased ris $\vec{e}$ of fatality.

The crude OR showed that involvement vans or light trucks was significantly associateâे with an increased risk of fatality. However, the risk was not significant after controlling for confounding factors in the multivariate analye sis.

\section{Discussion}

This study supplements the current literas ture $^{1-23}$ by quantifying the relationship be tween driver, environment, and crash and. vehicle characteristics and the severity of the crash. Risk factors that increased or decreased the risk of fatal and/or major, minor injur crashes compared with minimal injury crashes are documented in table 2.

This study uses crash data to examine the relationship between risk factors and the severity of crashes in which an injury occurre $\vec{b}$ The unit of observation is the crash involving young driver, not the young driver. The out come of the crash is determined by the mosi severe injury sustained by any individua involved in the crash. Note that this stud examines risk factors based on involvement in crash and not responsibility for crash initiation

\section{DRIVER CHARACTERISTICS}

Both the primary and secondary analyse indicated that fatal and major injury crashes are strongly and directly related to three ris factors-alcohol use, speeding, and not using seat belts.

Previous studies have shown that youn male drivers have a higher risk of involvemeno in traffic crashes than young female drif vers. $^{71627}$ Our results indicate, however, n\$ difference between young male drivers an $\mathbb{p}^{\mathrm{p}}$ young female drivers in terms of the severity of the crash given involvement in a crash invof ving injury. Young male drivers are reported i many Canadian studies to be more likely to engage in risky behaviors than young femats drivers, and male drivers are generally mores likely to drive daily, drive after drinking, drive over the speed limit, drive through yelloy lights, and change lanes more frequently than female drivers. ${ }^{28-30}$ They are also less likely to use seat belts. A recent report notes, howeves that young women are driving more, af engaging in more risky behaviors, and are involved in an increasing proportion of crashes than in the past. ${ }^{31}$ 
Alcohol use is reported to be strongly associated with increased risk of fatality in many studies. ${ }^{10-12}$ While the ORs for being involved in a fatal crash (OR $=2$ to $O R=5)$ obtained in our study are considerably below those for initiating a fatal crash $(O R=11.5)$, as reported by Perneger and Smith, ${ }^{32}$ the use of alcohol had a clear effect. Our study shows that speeding is strongly associated with alcohol use. Drinking drivers were less likely to use seat belts than drivers who were not drinking (72\% $v 95 \%$ ), consistent with Foss et al who report an OR 2.2 for non-use of seat belts among drivers with a BAC $0.1 \%$ or greater. ${ }^{33}$ Although we were unable to assess the impact of vehicle speed on crash severity because the information is not available in the TRAID database, Shibata and Fukuda state that a vehicle speed over $50 \mathrm{~km} /$ hour at the time of a crash increases the risk of fatality by a factor of $39 .{ }^{12}$ Nevertheless, our analyses do show that exceeding the speed limit increased the risk of fatality by a factor of 2.8 after controlling for other factors.

Not using seat belts and ejection were also independently and strongly associated with the risk of fatal injury crashes. Not using seat belts increased the risk by a factor of 4.7 for young drivers in our study compared with 2.9 for the drivers in a study by McGee and Rhodes. ${ }^{15}$ Few studies have quantified the effect of ejection from a vehicle on the risk of fatality; Esterlitz estimates that ejection increases this risk by a factor ranging from 2.5 to 25 if the victim is completely ejected. ${ }^{34}$ We determined that not using seat belts increases the risk of full ejection by a factor of 28 . Ejection occurred more often in head-on collisions, consistent with Esterlitz. ${ }^{34}$

\section{ENVIRONMENT}

Higher risk of fatality has been reported during summer months, weekends, and night hours. ${ }^{161735}$ Unlike previous studies, we control for confounding factors including alcohol use and speeding. The results of our study indicate that crashes occurring between $8 \mathrm{pm}$ and midnight had an increased risk of fatal outcome. Crashes occurring during summer months or on weekends, however, did not show an increased risk, indicating that alcohol use and speeding accounted for at least some of the increased risk during these time periods, as observed in previous studies and in our bivariate analysis.

The posted speed limit is a more controversial risk factor for fatalities. ${ }^{32021}$ Our analyses show that when the posted speed limit exceeded $60 \mathrm{~km} /$ hour, this risk increases. There was no demonstrated difference in risk, however, between roads with speed limits of 70$90 \mathrm{~km} /$ hour and $100 \mathrm{~km} /$ hour. As might be expected, increased risk of fatal injury crashes on roads with higher speed limits appears to be associated with the increased frequency of speeding, head-on collisions, and single vehicle collisions.

Snowy or icy road surface and rainy conditions may be inversely associated with fatal injury crashes (see table 2). It has been reported that crashes involving property damage alone and crashes involving non-fatal injuries occur more frequently on wet roads and during snowy weather ${ }^{1}$; the reduced risk of fatality may be due to drivers slowing down, being more cautious, or avoiding driving altogether. ${ }^{23}$ Only fog, sleet, or strong winds were found to increase, by a factor of 1.6, the risk of fatal injury crashes.

\section{CRASH CHARACTERISTICS}

The effect of crash configuration associated with young drivers has not been studied extensively in previous studies. ${ }^{18}$ Williams reports that crashes involving young drivers are more likely to be single vehicle collisions, and these are more likely to be fatal. ${ }^{16}$ Although we found that head-on collisions had a higher risk of fatality than single vehicle crashes, we consider single vehicle crashes to be an important factor responsible for fatalities: single vehicle crashes alone represent $45.6 \%$ of all fatal injury crashes in our study (see table 2 ).

\section{STRENGTHS AND LIMITATIONS}

This study has a number of strengths that support the credibility of our findings. First, the study, based on 1009 population based (fatal) cases and 41663 controls, has considerable statistical power to detect associations. Second, TRAID data items are well defined and wide ranging so that a number of potential risk factors can be examined. Third, data elements are generally complete: less than $1 \%$ of records have missing values. Finally, the data offer the opportunity to examine the effects of risk factors on severity of crash: fatal, major, or minor versus minimal injury. The gradient patterns of ORs observed in the study provide evidence for the causal associations.

There are, however, several limitations in the data provided by TRAID. One concern is that fatal injury, as defined by police, includes death up to 30 days after the crash, although an estimated $2 \%$ of deaths occur after 30 days (personal communication, S Fraser, Laboratory Centre for Disease Control, Health Canada, 1996). Another concern is the reliability of police reported levels of injury severity: some misclassification between levels is possible. ${ }^{36}$ Third is under-reporting of crashes, especially for minimal injury crashes ${ }^{37}{ }^{38}$; there may be differences in distribution between minimal injury crashes that are reported and those that are not. ${ }^{39}$ This may result in selection bias; it is difficult, however, to estimate the direction and magnitude of this bias. In general, missing data from controls would bias the ORs away from the null (that is overestimate the association), assuming that potential controls that were missing (in this case, minimal injury crashes not reported) were more likely to be exposed to the risk factors. Thus ORs regarding higher road speed limits, night hours, and alcohol involvement may be overestimated.

The OR for non-use of seat belts estimated 
in this study may be affected by the following two factors. Unlike other exposures, seat belt data were missing for $12 \%$ of cases and $8 \%$ of controls. In general, missing data for cases would bias the OR toward the null (that is underestimate the association) if a greater proportion of missing cases had the exposure of interest than those for which exposure data were available. For instance, it is possible that some data would be missing for a person who was killed immediately; it is also more likley that this person would not be wearing a seat belt. On the other hand, seat belt use is a self reported variable, and controls, those involved in minimal injury crashes, may over-report seat belt use: $95 \%$ of controls reported using seat belts compared with $85 \%$ observed in another survey conducted in Ontario. ${ }^{40}$ This would lead to overestimation of the OR.

The reliability of police reporting for alcohol use has been documented by Kim et al. ${ }^{5}$ The proportion of BACs determined by blood tests, breath tests, urine tests, or by observation alone is not available. Alcohol use may be under-reported in police reports, particularly where those involved were severely injured and taken to hospital. Similarly, evidence of speeding is not based on instrumentation, but on observations by police and/or statements by the driver or witnesses. ${ }^{5}$ However, it is unlikely that the direction or strength of the associations were affected substantially: measurement methods were comparable among cases and controls and the pattern of ORs for alcohol use and speeding was consistent for differing levels of severity.

This study was unable to consider other potential risk factors suggested in the literature $^{24142}$ such as driver's license status, driver education, or emergency medical response because these data were not available in TRAID. Moreover, information about drug use is incomplete.

The ORs estimated in this study reflect risk of fatality or major injury given that there is a crash and that there are injuries and do not necessarily represent risk of fatality or major injury among the general population of young drivers in Ontario. The ORs, however, provide quantitative evidence of risk factors for crash severity and indicate directions for examining these factors in the general population.

\section{Implications for prevention}

Prevention strategies for reducing fatalities from traffic collisions must focus on behaviors that place drivers in high risk circumstances. The primary targets for injury prevention are alcohol use, speeding, and seat belt use, which are shown here to be independent risk factors for severe crashes. Alcohol use and speeding contribute not only to the risk of initiating or being involved in crashes, as demonstrated in other studies, but also to an increased risk of fatality given that a crash has occurred, as demonstrated in this study.

In addition, the inter-relationship between risk factors should be considered. Reducing alcohol use, for instance, would reduce speed- ing and encourage seat belt use. Strategies to encourage responsible alcohol use should focus on young males and also on weekend and night time driving. Similarly, speeding should be $\overline{ }$. targeted to reduce fatalities on roads with high speed limits and single vehicle collisions. The? use of seat belts, which prevents ejection from vehicle, can substantially affect the risk of death? or major injury.

Head-on collisions, most significant of al: single risk factors, are clearly an important focus in preventing fatalities and major injuries in motor vehicle crashes. In addition tón behaviors such as not drinking, not speeding, $\overrightarrow{0}$ and using seat belts, drivers can be taught to chose lowest risk options to minimize the severity of a potential crash, for example $\overline{0}$ turning onto the road shoulder to avoid head $\omega$ on collision.

Current prevention stratagies in the province $\vec{\omega}$ of Ontario and elsewhere are targeting theseo behaviors. However, as demonstrated by Mun- ro et $\mathrm{al}^{43}$ legislation and regulatory control maycs be more effective than education alone. Oneo such legislative strategy is the graduated licen $\frac{\mathbb{D}}{3}$ sing system instituted in Ontario in 1994, which incorporates restrictions on new driverssuch as zero tolerance for alcohol use. Grad- $\bar{\phi}$ uated licensing in other jurisdictions appears to have a significant effect on reducing crash injuries for young drivers ${ }^{44}{ }^{45}$; this study provides baseline data for the period precedingo implementation of such legislation.

The authors thank Dr Catherine McCourt of the Bureau of Reproductive and Child Health for financial support and usefu comments on the manuscript. We also thank the staff of the Ontario Ministry of Transportation for providing data.

1 Ontario Ministry of Transportation. Ontario road safet annual report. Downsview, ON: Safety Research Office, Ontario Ministry of Transportation, 1990.

2 Levy DT. Youth and traffic safety: the effects of driving age experience, and education. Accid Anal Prev 1990; 22: 327-34.

3 Zlatoper TJ. Determinants of motor vehicle deaths in the United States: a cross-sectional analysis. Accid Anal Prevo 1991; 23: $431-6$.

4 Chipman ML, MacGregor CG, Smiley AM, Lee-Gosselin $\mathrm{M}$. The role of exposure in comparisons of crash risk among different drivers and driving environments. AcciB among different drivers and

$5 \mathrm{Kim} \mathrm{K}$, Nitz L, Richardson J, Li L. Personal and behavioraf predictors of automobile crash and injury severity. Accid Anal Prev 1995; 27: 469-81

6 Millar WJ, Last JM. Motor vehicle traffic accident mortality in Canada, 1921-1984. Am F Prev Med 1988; 4: 220-N

Massie DL, Campbell KL, Williams AF. Traffic accident involvement rates by driver age and gender. Accid AnaB Prev 1995; 27: 73-87.

8 Robertson LS. Injury epidemiology. New York: Oxford University Press, 1992.

9 Robertson LS. Patterns of teenaged driver involvement ipo fatal motor vehicle crashes: implications for policy choice. fatal motor vehicle crashes: implications for policy choice $\overline{\mathbb{D}}$

F Health Polit Policy Law 1981; 6: 303-14.
10 Simpson HM, Mayhew DR, Warren RA. Epidemiology of road accidents involving young adults: alcohol, drugs and other factors. Drug Alcohol Depend 1982; 10: 35-63.

11 Mounce NH, Pendleton OJ. The relationship between? blood alcohol concentration and crash responsibility for fatal injury drivers. Accid Anal Prev 1992; 24: 201 - 10.

12 Shibata A, Fukuda K. Risk factors of fatality in motor vehicle traffic accidents. Accid Anal Prev 1994; 26: $391-\sigma$ 7.

13 Moore VM, Dolinis J, Woodward AJ. Vehicle speed and risk of a severe crash. Epidemiology 1995; 6: 258-62.

14 Evans $L$. The effectiveness of safety belts in preventing facilities. Accid Anal Prev 1986; 18: 229-41.

15 McGee DL, Rhodes P. Estimating trends in the effective ness of seat belts in saving lives, 1975-1985. Stat Med 1989; 8: 379-85.

16 Williams AF. Nighttime driving and fatal crash involvement of teenagers. Accid Anal Prev 1985; 17: 1- 5. 
17 Kraus JF, Anderson CL, Arzemanian S, Salatka M, Hemyari P, Sun G. Epidemiologic aspects of fatal and severe injury urban freeway crashes. Accid Anal Prev 1993, 25: $229-39$.

18 Karpf RS, Williams AF. Teenage drivers and motor vehicle death. Accid Anal Prev 1983; 15: 55-63.

19 Evans L, Frick MC. Mass ratio and relative driver fatality risk in two-vehicle crashes. Accid Anal Prev 1993; 25: 213-24.

20 Wagenaar AC, Streff FM, Schultz RH. Effects of the 65 mph speed limit on injury morbidity and mortality. Accid Anal Prev 1990; 22: 571-85.

21 Lave C, Elias P. Did the $65 \mathrm{mph}$ speed limit save lives? Accid Anal Prev 1994; 26: 49-62.

22 Satterthwaite SP. An assessment of seasonal and weather effects on the frequency of road accidents in California. Accid Anal Prev 1986; 8: 87-96.

23 Brodsky $\mathrm{H}$, Hakkert AS. Risk of a road accident in rainy weather. Accid Anal Prev 1988; 20: 161 -76.

24 Robbins G. Traffic accident information database (TRAID) user's guide. Ottawa, ON: Road Safety, Transport Canada, 1993.

25 Hosmer DW, Lemeshow S. Applied logistic regression. New York: John Wiley and Son, 1989.

26 SAS Institute Inc. SAS/STAT software: changes and enhancements, release 6.10. Cary, NC: SAS Institute Inc, 1994.

27 Jonah BA. Accident risk and risk-taking behaviour among young drivers. Accid Anal Prev 1986; 18: 255-271.

28 Ministry of National Health and Welfare. National survey on drinking and driving 1988, overview report. Ottawa, ON: Ministry of National Health and Welfare, 1989.

29 Transport Canada. Concern for road safety: a national survey of drivers. Ottawa, ON: Road Safety, Transport Canada; 1987.

30 Ontario Ministry of Health. Ontario health survey 1990 Toronto, ON: Ontario Ministry of Health, 1993.

31 Wylie SJ. Young female drivers in New Zealand. Accid Ana Prev 1995; 27: 797-805

32 Perneger T, Smith GS. The driver's role in fatal two-car crashes: a paired 'case-control' study. Am 7 Epidemiol
1991; 134: $1138-45$

33 Foss RD, Beirness DJ, Sprattler K. Seat belt use amon drinking drivers in Minnesota. Am F Public Health 1994; 84: $1732-7$.

34 Esterlitz JR. Relative risk of death from ejection by crash type and crash mode. Accid Anal Prev 1989; 21: 459-68. 35 Waters C, Gibbons L, Robert S, Semenciw R, Mao Y. Maters C, Gibbons L, Robert S, Semenciw R, Mao Y.
Motor vehicle traffic accidents in Canada, 1978-87 by time of occurrence. Can $\mathcal{F}$ Public Health 1993; 84: 58-9.

36 Austin $\mathrm{K}$. The identification of mistakes in road acciden records: part 2 casualty variables. Accid Anal Prev 1995; 27: $277-82$.

37 Rosman DL, Knuiman MW. A comparison of hospital and police road injury data. Accid Anal Prev 1994; 26: 215 22

38 Bull JP. Data sources for accident modelling. Accid Ana Prev 1986; 18: 79-83.

39 Hauer E, Hakkert AS. Extent and some implications of incomplete accident reporting. Transportation Research Record 1988; 1185: 1 - 10 .

40 Andersen J. 1991 Ontario roadside seat belt survey results. Downsview, ON: Research and Evaluation, Ontario Ministry of Transportation, 1992

41 Jones AP, Bentham G. Emergency medical service accessibility and outcome from road traffic accidents. Public Health 1995; 109: 169-77.

42 Ray WA, Fought RL, Decker MD. Psychoactive drugs and the risk of injurious motor vehicle crashes in elderly drivers. Am $\mathcal{f}$ Epidemiol 1992; 136: 873-83.

43 Munro J, Coleman P, Nicholl J, Harper R, Kent G, Wild D. Can we prevent accidental injury to adolescents? A systematic review of the evidence. Injury Prevention 1995; 1: 249-55.

44 Ferguson SA, Leaf WA, Williams AF, Preusser DF. Differences in young driver crash involvement in states Differences in young driver crash involvement in states
with varying licensure practices. Accid Anal Prev 1996; 28: with varying $171-80$.

45 Langley JD, Wagenaar AC, Begg DJ. An evaluation of the New Zealand graduated driver licensing system. Accid Anal Prev 1996; 28: 139-46.

\section{\$35 million for ATV injuries}

A jury in Alabama issued a judgment against Yamaha Motor Co for compensatory damages of $\$ 35$ million. The award is to a 20 year old who suffered severe brain damage after the four wheel all terrain vehicle he was driving overturned on a dirt road (Baltimore Sun, 1 June 1996).

\section{Boy kills brother with revolver}

A 15 year old shot and killed his 2 year old brother with a revolver; he has pleaded guilty to delinquent behaviour. The youth was smoking marijuana and drinking beer when the incident occurred (D Martelli, Boston Globe, 6 June 1996).

\section{Another dog versus child paradox}

In New Hampshire (whose motto is 'Live Free or Die') it is now illegal to transport dogs in the back of a pickup truck unless they are safely restrained. This law does not apply to children!!

\section{Helmet damages pick-up truck}

An 8 year old bicyclist in Lancaster, MA, who was struck by a truck that had skidded more than 75 feet, survived because of his helmet. 'The impact from the helmet put a hole in the grille of the pick-up truck', police observed. The child's own comment: 'Better wear a helmet. It hurts a lot if you don't' (A Brockelman, Fitchburg Sentinel Enterprise, 31 May 1996). 